\title{
Multidimensional Assessment of Emotion Regulation and Dysregulation: Development, Factor Structure, and Initial Validation of the Difficulties in Emotion Regulation Scale
}

\author{
Kim L. Gratz • Lizabeth Roemer \\ Published online: 17 October 2008 \\ (C) Springer Science + Business Media, LLC 2008
}

\section{Erratum to: J Psychopathol Behav Assess (2004) 26:41-54 DOI 10.1023/B:JOBA.0000007455.08539.94}

In stating that the Generalized Expectancy for Negative Mood Regulation Scale (NMR; Catanzaro \& Mearns, 1990) was used as a template to help structure the format (but not the content) of the Difficulties in Emotion Regulation Scale (DERS), we failed to specify that one of the DERS items (\# 35, "When I'm upset, I believe that wallowing in it is all I can do.") is identical in wording to an NMR item, and another (\#20, "When I'm upset, I believe that I'll end up feeling [very] depressed.") is almost identical in wording, while three other DERS items (\# 19, 32, and 34) are similar in content to NMR items. Thus, 5 of the 36 items in the DERS are content-related to the NMR. Further, three other DERS items (\# 12, 21, and 39) were adapted from items in the Emotional Approach Coping Scale (Stanton, Kirk, Cameron, \& Danoff-Burg, 2000) and four others overlap with items from the Trait Meta-Mood Scale (Salovey, Mayer, Goldman, Turvey, \& Palfai, 1995). Finally, to clarify the statement that "many DERS items begin with 'When I'm upset,' similar to the NMR (p. 44)," it should be noted that 27 of the 36 items begin with this phrase (just as all of the NMR items do).

The online version of the original article can be found at http://dx.doi. org/10.1023/B:JOBA.0000007455.08539.94.

\footnotetext{
K. L. Gratz • L. Roemer

Boston, MA, USA

Present address:

K. L. Gratz $(\triangle)$

Department of Psychiatry and Human Behavior,

University of Mississippi Medical Center,

2500 North State Street,

Jackson, MS 39216, USA

e-mail: KLGratz@aol.com
}

Department of Psychology, University of Massachusetts Boston, 